\title{
ANALYSIS OF THE RESULTS IN IMPLEMENTING THE OPERATIONAL PROGRAM FOR HUMAN RESOURCES DEVELOPMENT 2007-2013 FOR CENTER REGION, ROMANIA
}

\author{
Ionela Gavrilă-Paven ${ }^{1}$, \\ Iulian Bogdan Dobra', \\ Lucian Docea ${ }^{3}$
}

\begin{abstract}
This study aims to highlight the results achieved through the implementation of projects financed by the European Social Fund through the Operational Program for Human Resources Development 2007-2013 at regional level. It was considered Center Region for the presentation and analysis of data from the point of view of absorption and especially from the point of view of the results obtained by analyzing outcome indicators reported by the recipients for 20072012. Although the degree of absorption is relatively low, it was found that a large proportion of people who participated in the project activities have gained superior skills to those achieved before insertion into the labor market. Such results are not always immediately measurable, but certainly have led to the increase of the flexibility and generated a labor market mobile in the analyzed region.
\end{abstract}

Keywords: economic development, human development, regional economic development

JEL Codes: O12, O15, R11, R58

\section{Introduction}

European Union Cohesion Policy aims to reduce disparities between the developed regions and Member States of the Union and the ones less developed. The legal basis for this policy is the Treaty on European Union (Title XVII "Economic and Social Cohesion" and Article 148 on the European Social Fund). The article 158 from the Treaty of Amsterdam states cohesion as a precondition for the harmonious development of the European Union, stating the intention of "reducing disparities between the levels of development of the various regions and the backwardness of the least favored regions or islands, including rural areas".

In developing the new financial framework for 2014-2020, the European Commission introduced the "Connecting Europe Facility", which is a completely new scheme to finance priority infrastructure of pan-European interest in transport, energy and ICT. The financing of this facility will be achieved by introducing a new section in the European Union budget foreseeing an allocation of 50 billion Euros. European Commission considered reuniting the European Regional Development Fund, European Social Fund and the Cohesion Fund in a common strategic framework to include the European Agricultural Fund for Rural Development and the European Fisheries Fund. In this framework, European Commission desires to establish partnerships with each Member State, in order to achieve results-based programming. These partnerships will include macroeconomic conditions to improve coordination of economic policies of the Member States (European Commission, 2011).

\footnotetext{
1 "1 Decembrie 1918” University of Alba Iulia, Romania, e-mail: ionelapaven@yahoo.com

2 "1 Decembrie 1918” University of Alba Iulia, Romania, e-mail: dobra.iulian@uab.ro

3 "1 Decembrie 1918" University of Alba Iulia, Romania, e-mail: lucian.docea@gmail.com
} 
European Social Fond will support structural actions for economic, social and territorial cohesion through four main investment areas: employment, education, social inclusion, improving public administration, helping to achieve the objectives of Europe 2020. This fund will be supported by the European Globalization Adjustment Fund, which will continue to provide support for unemployed workers generated by the major structural changes. In addition, the Fund will expand its scope to reduce the impact of new trade agreements on farmers (European Commission, 2011).

\section{Literature review}

European Social Fund, respectively Operational Program for Human Resources Development 2007-2013, are tools that support investments in education, research and development and in creating new jobs. This type of investment can be explained scientifically as Human Capital Theory (Becker, 1993). This theory can be applied to both microeconomic and macroeconomic level. Considering the microeconomic approach (Chapman, 1993) it should be considered measurable benefits, i.e. salaries, employment, labor productivity, exports and so on, compared with the efforts, or working hours, wage taxes, production decreases. Concluding, both individuals and companies should invest in human resources starting with the moment when the benefit outweighs the cost. Using Human Capital Theory and supplementing it with the discrimination analysis (Spence, 1975), the dual nature of human nature (Reynolds et al, 1993) and the struggle between classes (Bowles and Gintis, 1975) it is obtained a descriptive framework of microeconomic labor market. Thus, some people can get greater rewards and more opportunities than others due to the signaling right, compared to other people that send inappropriate signals and will get small rewards for their work and fewer opportunities for their future development. More, the development of small and medium enterprises sector shows that they do not pay attention to major investments in training and qualification as for large companies, and opportunities for advancement are smaller and more limited compared to their (Eduardo Tome, 2001 2009, 2013). These differences may lead in time to market imbalances, which can be corrected by state intervention through its available levers. These imbalances can be caused by lack of information, evaluation and risk taking, poverty etc. (Middleton et al, 1991). State may interfere in such situations by providing funds or building and providing necessary training. Another assumption of state intervention is the hypothesis of interfering in removing inefficiencies in the labor market, capital market or technology market (Middleton et al, 1991). The benefits of interventions and investments to support human resource development are significant and can be scientifically assessed by means of control groups (Heckman, Lalonde and Smith, 1999). Society should support public policies because their purpose is to create a social good. However, if it appears that the efforts made to interfere in the market are higher than the benefits from this intervention, the public intervention should be stopped (Eduardo Tome, 2001, 2009, 2013).

At the macroeconomic level the investments made in human resources in different societies are generating low, average and high equilibrium (Ashton and Green, 1996; Schultz, 1961). In a low equilibrium, small investments are made on jobs demand with low skills, and on the other hand the staff of organizations with low skills and qualifications can achieve only investments that will have small impact; this vicious circle determines low level of productivity, skills and investment and local effects; this type of investment is usually encountered in underdeveloped economies. In opposition, in a functional economy, investment in capacity building are high and companies require jobs that involve highly skilled workforce that will generate higher productivity; so, in this type of society it can be observe a virtuous circle of efficiency. The average equilibrium is specific for emerging economies. In these economies, investments are rising in the same time with the increase of the productivity; these factors will lead to increase of the demand for highly skilled labor. At the macroeconomic level, state presence in the economy is explained by the need to 
eliminate the vicious circle of low balance and to lead the economy to a high-level equilibrium (Eduardo Tome, 2001, 2009, 2013).

\section{Major obstacles for economic growth and employment}

In the Spring European Council held from 25 to 26 March 2010 the European Commission was asked to identify the main obstacles that constrain growth at European Union level. In close cooperation with the European Commission, Member States identified at national level these obstacles.

As for our country, approaching identified obstacles at macroeconomic level requires the creation of a framework conditions on long-term in order to solve macro and fiscal and external imbalances. Equally, it is necessary to develop policies aimed to unlocking the main engine of economic growth, with real macroeconomic impact: employment policies, market products, innovation, research and development, climate change and education (National Reform Program 2011-2013, 2011).

Thus, according to the National Reform Program 2011-2013 prepared by the Romanian Government in 2011, the main macroeconomic obstacles identified are concerning: (1) high structural deficit of the consolidated budget, (2) low level of efficiency, effectiveness and independence of public administration, including the absorption capacity of structural instruments, (3) reduce the risks to financial stability, (4) poor functioning of the labor market, especially in terms of the wage bargaining system; measures for labor market flexibility and improvement of the business environment implemented through National Reform Program 2007-2010 had limited effects, but they are still a priority for 2011-2103, (5) failure contribution of the educational system at all levels to human capital formation; in order to develop the Romanian educational system and to adapt it to the current requirements of the knowledge based society, the Romanian Government designed a new National Education Law - Law no. 1/2011; this law contains regulations that, on medium and long term, are expected to generate quality human capital formation, to support smart, sustainable and inclusive growth.

Social inclusion of vulnerable groups and their transformation from groups of welfare recipients in various forms into contributors to the national budget, is one of the national objectives that our country has assumed to the European Union for the next period. The national objective is to reduce by 580,000 until 2020 , the number of persons at risk of poverty and social exclusion compared to 2008 , representing a $15 \%$ reduction in the number of people living in poverty.

\section{Courses of action for achieving the objective}

According to the National Reform Plan 2011-2013, the main directions of action for achieving the objective are: (1) the active social inclusion supported by developing incomegenerating activities and services to help people at risk of social exclusion to integrate or reintegrate into the labor market, social economy enterprises and/or in the formal economy, developing specific programs for (re)integration into the labor market of persons belonging to vulnerable groups and training for basic skills and qualifications for them. Groups concerned are Roma people, people with disabilities, young people under 18 who leave the child protection system, people living based on income support, homeless people, people living in isolated communities etc.. For the period 2011-2013 are expected to be created 500 social economy structures and 10,000 jobs in the social economy of these structures and 150,000 people will participate in (re)qualification programs for vulnerable groups, (2) development of social infrastructure - the economic crisis of recent years has affected the unequal regions of the country, with significant regional disparities in terms of poverty rates. The region with the highest rate of relative poverty in 2008 is the North East $(27.2 \%)$ and the least poor were the Bucharest - Ilfov (4.7\%). Also, there is a high poverty rate in the South - West $(23.3 \%)$ and South - East $(22.7 \%)$. 


\section{Research methodology}

The main objective of this study is to evaluate the results of implementation the projects financed by the European Social Fund, respectively through the operational Program for Human Resources Development 2007-2013, in the Center Region. This study focuses on concrete results that were made available for the authors by the Intermediary Regional Bureau for Center Region for period 2007-2012.

Towards achieving this objective in terms of typology investigative approach we used the qualitative research methods, and finally we can draw conclusions of the research. Therefore, techniques and procedures used in this research were: field study that legislative acts of Regulation (EC) no. 1083/2006, Regulation (EC) no. 1260/1999, Regulation of the European Community no. 2988/1995 of the European Council, December 18th 1995, Euratom and Convention regarding the Protection of the Financial Interests of the European Communities, July 26th 1995; bibliographic documentation by studying the works of authors in the field of European funds, documentation of projects implemented or under implementation (in number of over 50 such projects); classification / sorting consisted of placing information in a particular order, well-established criteria and not least descriptive analysis used in the present relationship between beneficiaries and authorities coordinating and managing the public financial resources in terms of a fair and efficient management of EU funds.

In developing the study were analyzed the key areas of intervention that were opened for applications for projects in the period 2007-2012 and have requested financing in this period. Projects included in this study had been or were in progress during 2007-2012 in the following areas of intervention: Area 3. Increasing adaptability of workers and enterprises, Axis 3.1. Promoting entrepreneurial culture, Axis 3.2. Training and support for enterprises and employees to promote adaptability, Area 5. Promoting active employment measures, Axis 5.1. Developing and implementing active employment measures, Axis 5.2. Promoting long-term sustainability of rural areas in terms of human resource development and employment, Area 6. Promoting social inclusion, Axis 6.1. Social economy development, Axis 6.2. Improving access and participation of vulnerable groups in the labor market, 6.3 Promoting equal opportunities on the labor market.

\section{Data analysis}

Absorption of European funds has reached by the end of July 2013 to $19.10 \%$ and for the Operational Program for Human Resources Development 2007-2013 it reached 16.62\%. Note that this rate has increased significantly this year, respectively from $6.34 \%$ level in May 2012 to $16.62 \%$ in July 2013. The operational program has been suspended by the European Commission in early August 2012 as a result of deficiencies identified by the Community experts for 2009-2011. In early February 2013, representatives of the European Union decided to release Operational Program for Human Resources Development 2007-2013 and the reimbursement of payments for our country as a result of positive results from the engagement of the European Commission, held from January $29^{\text {th }}-$ February $1^{\text {st }} 2013$. In terms of amounts, our country managed to absorb for the Operational Program for Human Resources Development 2007-2013 until the end of July 2013 up to the amount of 577,704,411 Euros.

The analysis conducted in this study aims to highlight the results of implementing projects financed through the Operational Program for Human Resources Development 2007-2013 as intermediary and final reports submitted by beneficiaries for 2007-2012. For this period, the absorption coefficient reached $7.72 \%$ on $31^{\text {st }}$ December 2012, representing an absolute amount recoverable of 268,344,046 Euros.

In terms of number of participants for the first time in operations financed by the European Social Fund, considering the areas of intervention it can be seen that in the analyzed period, respectively, during 2007-2012, the highest percentage was recorded for Axis 5.2. Promotion long term sustainability of rural areas in terms of human resource development and employment, with a 
number of 52,057, which represents in relative size approximately $44 \%$ of all participants. This was followed by Axis 5.1. Developing and implementing active employment measures with more than $24 \%$, respectively a total of 28,674 participants, and Area 6.1. Developing the social economy by about $10 \%$, respectively 11.809 participants.

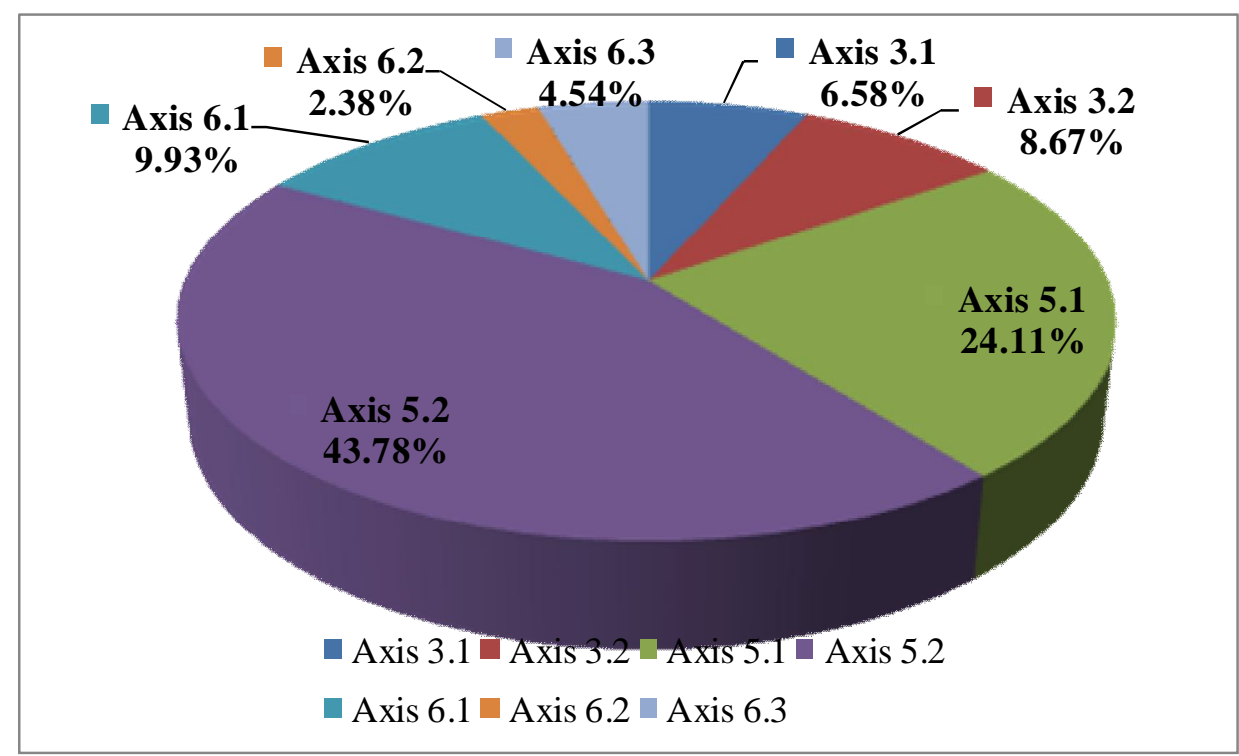

Figure no. 1. - Structure of participants in ESF operations

Source: authors' own processing after data offered by Intermediary Regional Bureau for Operational Program for Human Resources Development, Center Region, 2013

Regarding the participation of the target group learners for the operations financed through European Social Fund, considering the areas of intervention, it may be noted that in the analyzed period, there were three major axis of intervention that recorded a level of certification over 50\%, i.e. Axis 5.1 Developing and implementing active employment measures, with a percentage of $59.62 \%$, Axis 6.1 Developing the social economy, with a percentage of 57.98\%, respectively, Axis 6.3 Promoting equal opportunities on the labor market with a percentage of $55.22 \%$. This was followed at a "distance" of over 16\% of the other major axis as it can be seen in Figure no. 2 Level of certification for participants in European Social Fund operations.

The following data must be correlated with the type of business permitted by the guidelines of intervention; it is obvious that those who were included in projects and aimed at training as an extra chance of entering the labor market, the certification for participants is higher. We have reservations regarding Axis 5.2., which has the lowest level of participation related to the relevance of strict orientation to redirect participants exclusively outside agriculture. This seems to be perceived by them as being the best choice or strategy, given by the labor market in rural areas. If we take into account the qualifications for people working in agriculture form of (semi-) subsistence we can conclude that for some people out of subsistence agriculture rather could lead to permanent employment in agriculture and related activities than the prospect of working in other sectors such as nonagricultural. 


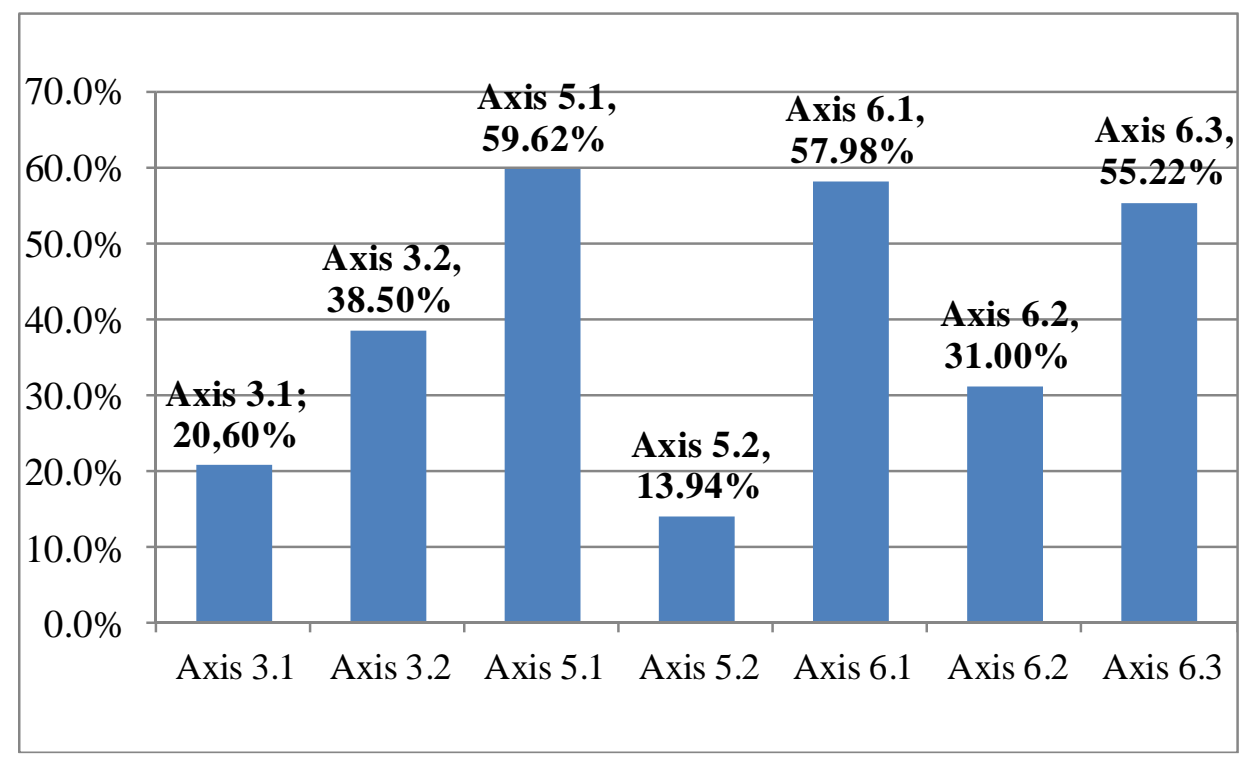

Figure no. 2. - Level of certification for participants in European Social Fund operations Source: authors' own processing after data offered by Intermediary Regional Bureau for Operational Program for Human Resources Development, Center Region, 2013

Depending on the type of the target group participants at operations financed through European Social Fund, it may be noted that in the analyzed period, the situation is as it follows: the total number of women was 64,193 , while that of men was 53,326 persons. In the areas of intervention is noted that the number of women exceeds that of men in all four areas of the seven analyzed axis.

Axis 5.2. Promoting long-term sustainability of rural areas in terms of human resource development and employment and Axis 5.1. Developing and implementing active employment measures represent almost $70 \%$ of the beneficiaries of the analyzed projects in this study; the unemployment is higher among women than men and are more women willing to participate in training programs compared to men; based on these, it is obvious that women have the highest weight in the activities of the project.

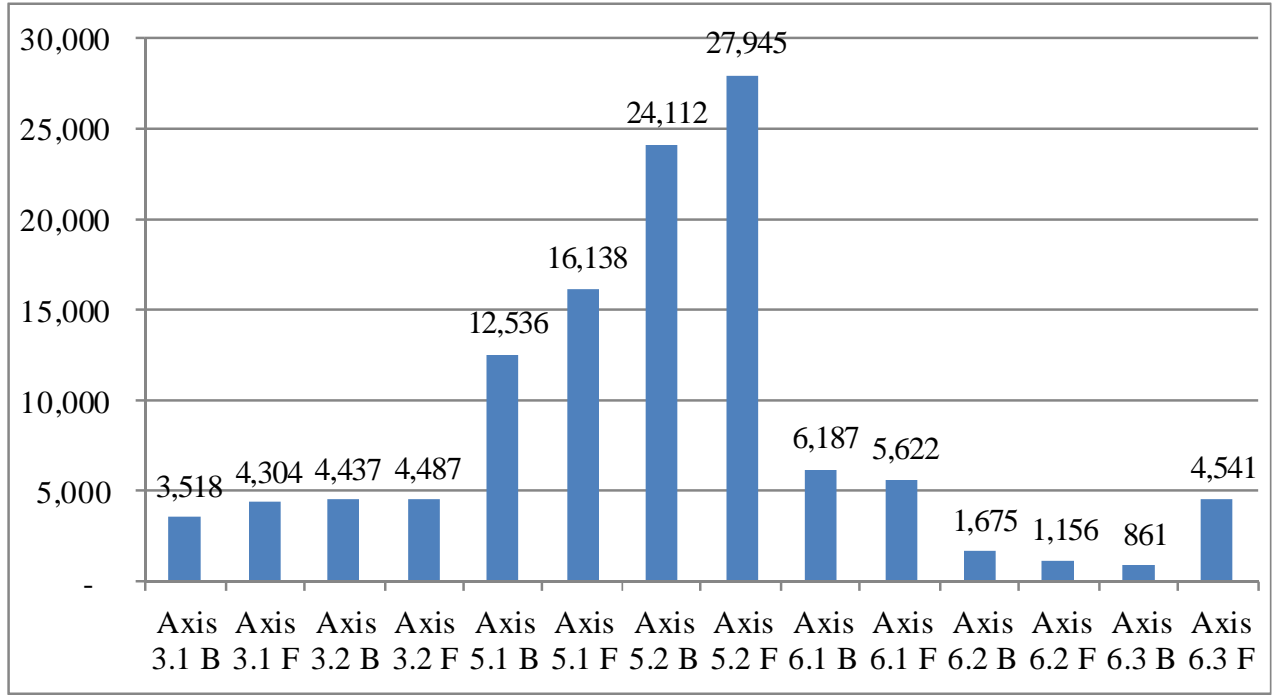

Figure no. 3. - Structure by gender of the participants in the operations financed through Social European Fund 
Source: authors' own processing after data offered by Intermediary Regional Bureau for Operational Program for Human Resources Development, Center Region, 2013

As can be seen from Figure no. 3 Structure on gender of the participants in operations financed through European Social Fund Axis 5.2 Promote the long-term sustainability of rural areas, in terms of human resource development and employment, the number of women is higher by 3,833 persons compared to the number of men, and for the Axis 6.3 Promoting equal opportunities on the labor market, he number of women is higher by 3,680 persons compared to the number of men.

Depending on the status recorded on the labor market, it can be observed that the number of un employed participants in the first three areas of intervention is high: for the Axis 5.1 Developing and implementing active employment measures recorded a total of 25,899 unemployed, of which 7,954 persons are long-term unemployed; for the Axis 5.2 Promoting long-term sustainability of rural areas in terms of human resource development and employment, the number of unemployed persons was over 19,000, of which 3,662 persons are long-term unemployed; and, for the Axis 6.1 Social economy development, recorded a number of 1,120 persons unemployed, of which 612 persons long-term unemployed.

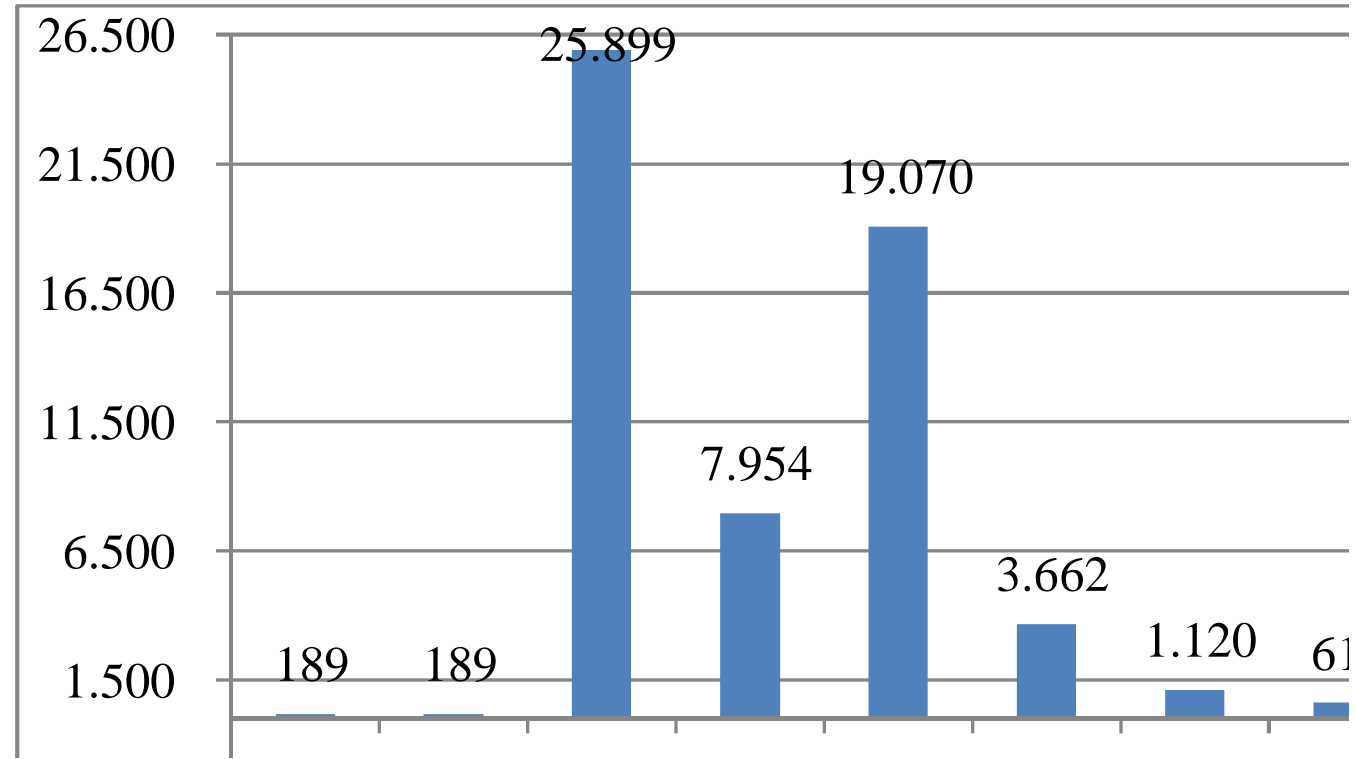

\section{Figure no. 4. - Structure by gender of the participants to the operations financed through European Social Fund}

Source: authors' own processing after data offered by Intermediary Regional Bureau for Operational Program for Human Resources Development, Center Region, 2013

The above data reflects a normal situation considering the target groups of the 5 key areas of intervention. Only Axis 5.1. Developing and implementing active employment measures and Axis 5.2. Promoting long-term sustainability of rural areas in terms of human resource development and employment focuses especially on unemployed persons, so the other three axes are underrepresented compared to the other two axes presented above.

Regarding the total inactive participants in the operations financed through European Social Fund in the analyzed period, it is noted that the most significant weight is given by the inactive persons in education and training by $71 \%$, which in absolute size is 25,876 persons and homemakers by $7 \%$, representing 2,641 persons in absolute size. The graphical representation is shown in Figure no. 5 Weight of inactive participants in operations financed through European Social Fund. 


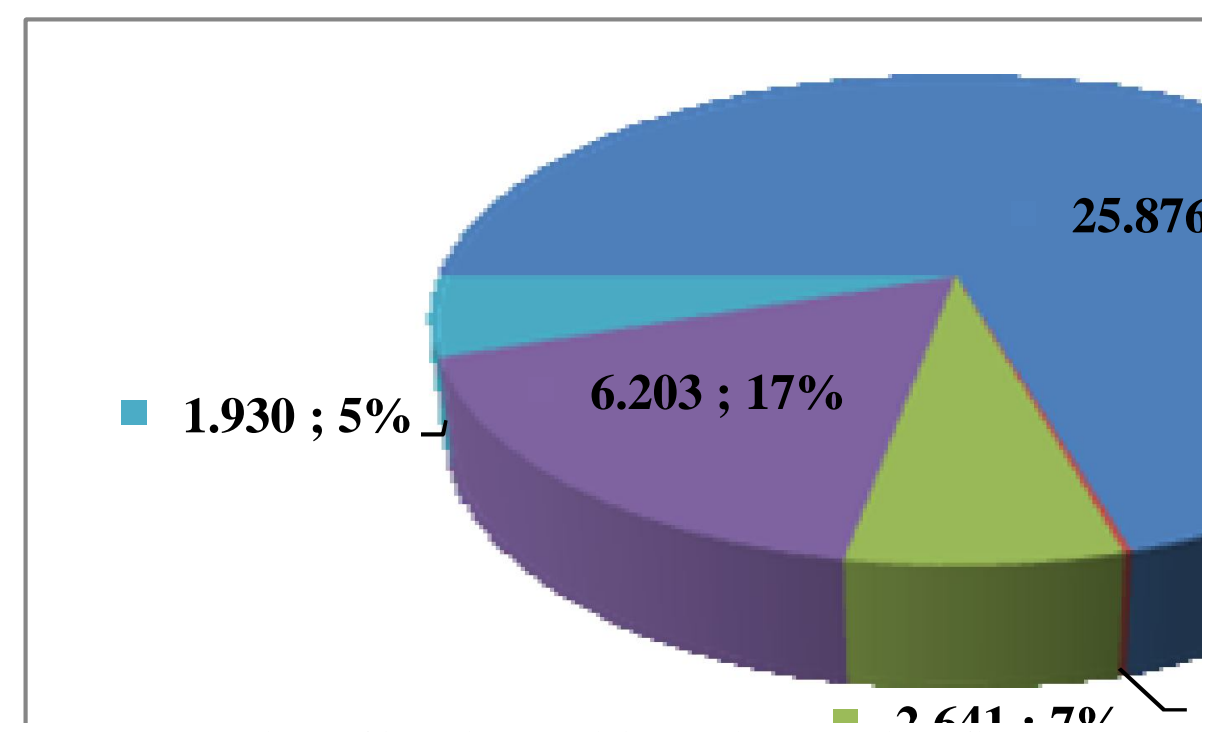

Figure no. 5. - Weight of inactive participants in operations financed through European Social Fund

Source: authors' own processing after data offered by Intermediary Regional Bureau for Operational Program for Human Resources Development, Center Region, 2013

In terms of total number of inactive persons participating in operations financed through European Social Fund, considering the intervention areas in the analyzed period, the situation is as it follows: Axis 5.2 Promoting long-term sustainability of rural areas in terms of human resource development and employment includes the largest number of inactive persons with more than 21,000 students, followed by Axis 6.1 Social economy development with a total of over 9,000 persons.

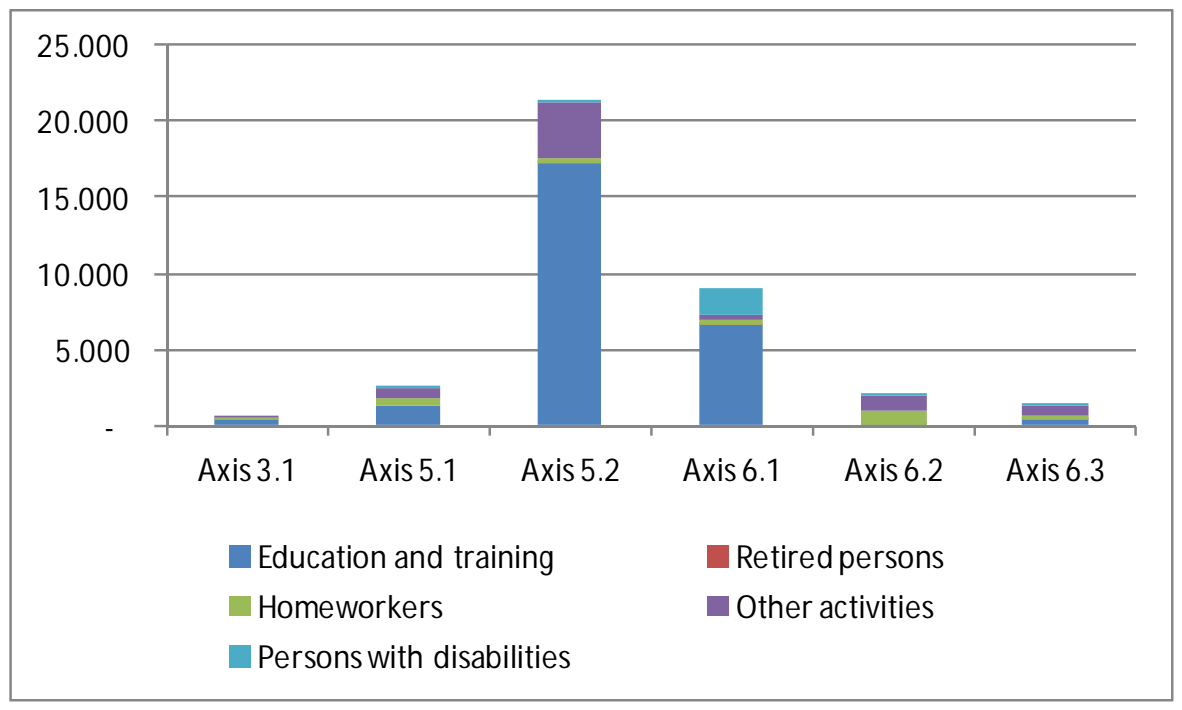

Figure no. 6. - Structure of inactive persons on intervention axes

Source: authors' own processing after data offered by Intermediary Regional Bureau for Operational Program for Human Resources Development, Center Region, 2013

Considering the age of participants, it can be noted that the most significant weight is given to all young students about 22,000 participants, approximately $75 \%$ of the total, the difference being represented by the elderly over $25 \%$, which in absolute values are 7,468 people. 


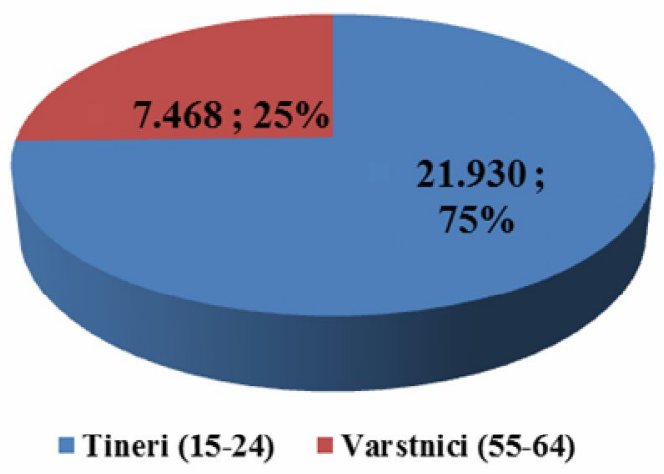

Figure no. 7. - Structure on age of the inactive participants

Source: authors' own processing after data offered by Intermediary Regional Bureau for Operational Program for Human Resources Development, Center Region, 2013

In the analyzed period, for all areas of intervention, the weight of young person's is higher than the elderly persons. So, for the Axis 5.2 Promoting long-term sustainability of rural areas in terms of human resource development and employment number of young persons is higher by 6,441 persons than the elderly persons, in the Axis 5.1 Developing and implementing active employment measures the number of young persons is higher by 5,569 than the elderly persons, and for Axis 6.1 Social economy development the difference is of 864 persons for young participants.

All data shown reveals that young persons are more active in the labor market. Also, it can be concluded that they are more willing to participate in such projects and qualify/(re)qualify or follow training programs in new areas.

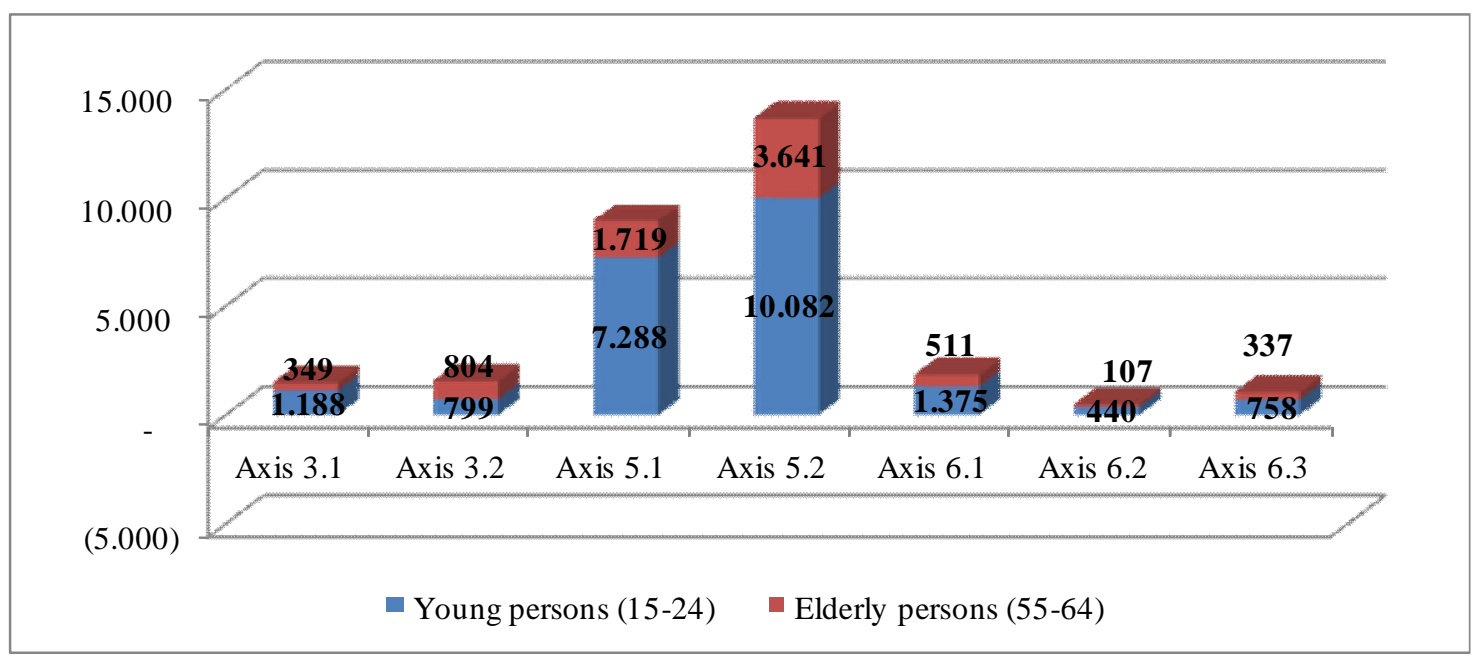

Figure no. 8. - Structure by age for the participants in operations financed through European Social Fund

Source: authors' own processing after data offered by Intermediary Regional Bureau for Operational Program for Human Resources Development, Center Region, 2013 


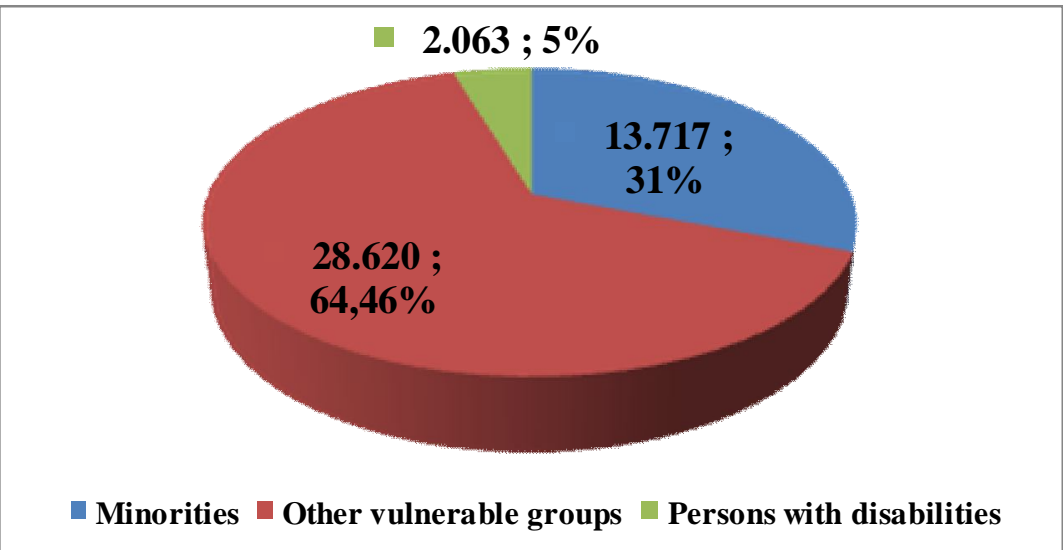

\section{Figure no. 9. - Structure on vulnerable group of the participants to the operations financed through European Social Fund}

Source: authors' own processing after data offered by Intermediary Regional Bureau for Operational Program for Human Resources Development, Center Region, 2013

Considering the structure of participants by vulnerable group it appears that the most significant share is held by the Other disadvantaged groups, respectively, $64.46 \%$ of the total, which is the absolute size of 28,620 participants. Minority group accounts for approximately $31 \%$ of all participants, and persons with disabilities $5 \%$.

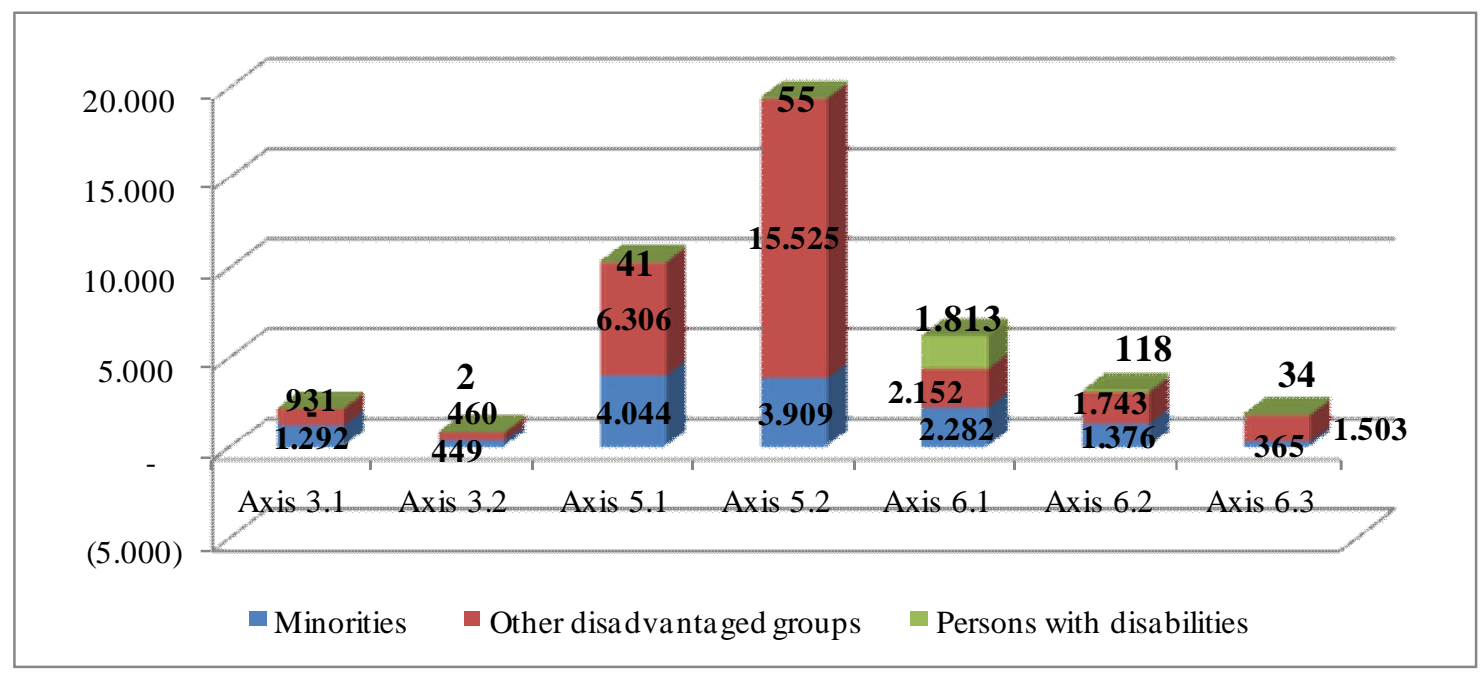

Figure no. 10. - Structure of the participants considering the vulnerable group

Source: authors' own processing after data offered by Intermediary Regional Bureau for Operational Program for Human Resources Development, Center Region, 2013

Considering the vulnerable group of the participants, correlated to the areas of intervention, it can be seen: Axis 5.2 Promote the long-term sustainability of rural areas in terms of human resource development and employment there are recorded 19,000 persons, of which over 15,000 are in category other disadvantaged groups and minority group around 4,000 persons, in favor of young people; for the Axis 5.1 Developing and implementing active employment measures indicates a total of 10,391 persons, of which the share most significant is owned by other disadvantaged groups with 6,306 persons; and for Axis 6.1 Social economy development there have been recorded a total of 6,247 persons, out of which 2,282 persons are from minorities and 2,152 persons have disabilities. 


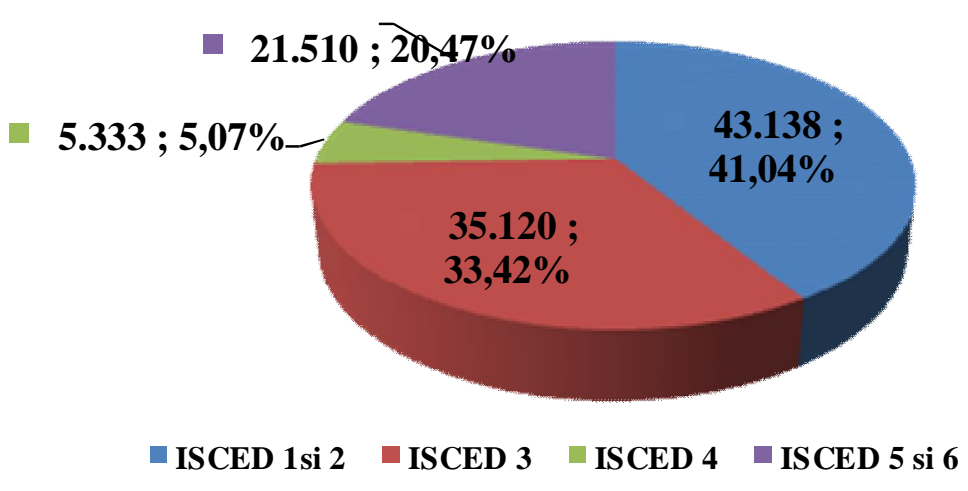

Figure no. 11. - Structure of participants considering educational level

Source: authors' own processing after data offered by Intermediary Regional Bureau for Operational Program for Human Resources Development, Center Region, 2013

Considering the structure of participants by educational level it can be observed that in the analyzed period, the most significant share is held by people who have primary or secondary education, respectively, 41.04\%, which in absolute size means a number of over 43,000 participants. These are followed by the category of persons of upper secondary graduates with $33.42 \%$ of the total, representing over 35,000 persons and persons that graduated university and post-university with $20.47 \%$, respectively, over 21,000 participants.

Due to the evolutions recorded on the labor market lately, it can be seen that there is a tendency to adapt to the requirements of persons in the position of losing their jobs or who have already lost it. In this sense, as a strategy for survival on the labor market, people with low education are more willing to participate in such projects than those with a medium level of education. It can be observed that there is a significantly higher level of availability for those who have a high level of education, which in turn are willing to exploit the opportunities offered by these projects to acquire new skills and abilities.

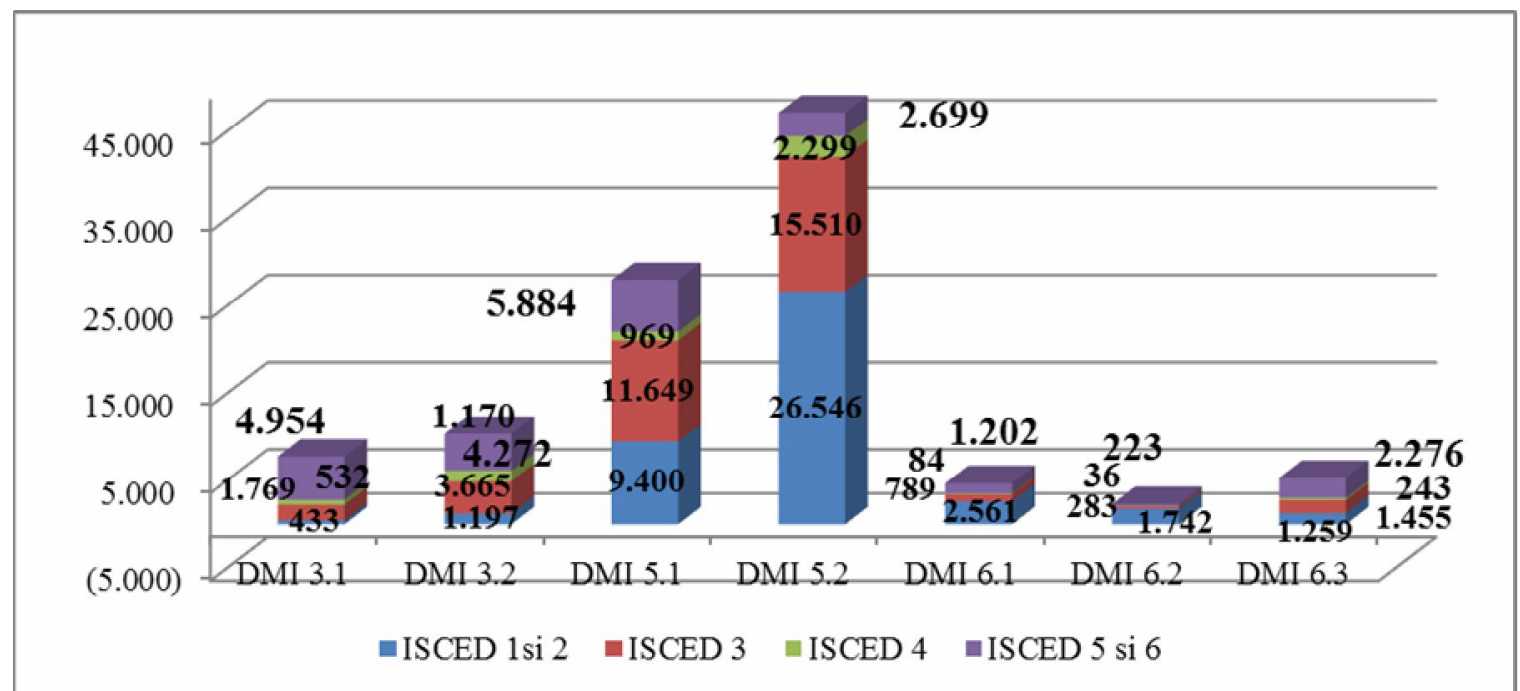

\section{Figure no. 12 Structure on educational level of the participants to the operations financed through European Educational Fund}

Source: authors' own processing after data offered by Intermediary Regional Bureau for Operational Program for Human Resources Development, Center Region, 2013 
Considering the educational level for the areas of intervention analyzed, it can be observed that: for the Axis 5.2 Promoting long-term sustainability of rural areas in terms of human resource development and employment were recorded over 47,000 persons, out of which 26,546 are persons with primary or secondary education, 15,510 persons graduated upper secondary education; for the Axis 5.1 Developing and implementing active employment measures the number of youth is about 29,000 people, out of which 11,649 are upper secondary graduates and 9,400 persons with primary or secondary education; for the Axis 3.2 Training and support for enterprises and employees to promote adaptability from the total of 10,304 participants out of which 4,272 persons graduated university and post-university education and 3,665 persons graduated secondary education.

\section{Conclusions}

Since the beginning of the implementation of the Operational Program for Human Resources Development 2007-2013 there were contracted over 2400 projects. Within these projects there were involved thousands of partners from the country and abroad, with various forms of organization: ministries, local authorities, public institutions at all levels, private companies, social partners, universities, colleges and schools, NGOs etc. , all profiles and sizes.

The impact of the implementation of the entire program will involve the absorption of 4 billion Euros allocated directly, there will be created at least 18,000 jobs within project teams, there will be generated contributions for the state budget, social security and health VAT of nearly 1.8 billion Euros. In addition to these direct benefits related to the organization of project implementation, there has to be added the benefits that should result from the actual project implementation and achievement of the assumed indicators by every beneficiary. These commitments are related to the target group clearly stated in the application submitted for funding and the activities that have to be developed for the persons targeted in projects.

From the this analysis, which included projects from seven intervention areas in the Center Region, Romania, it is clear that the benefits are much broader than what is strictly related to the organization of project implementation. A large proportion of people who participated in training activities, the activities of counseling, mediation and employment placement, development of entrepreneurial skills superior to those acquired before entering the labor market were able to find working places or opening their own business through project activities and even financial support for starting up. Such results are not always immediately measurable, but certainly lead to an increased flexibility and mobility of greater labor market and therefore at least one of the objectives of the program has been reached. For human resources, the effect of quantitative accumulation of seemingly small-scale effects, sometimes even point, will ultimately lead to a qualitative leap, raising human capital of Romania at a competitive level.

\section{References}

1. Ashton D., Green F., 1996. Education, Training and the Global Economy, Edward Elgar, Cambridge UK; pp 100-4.

2. Becker G., 1993. Human Capital: A Theoretical and Empirical Analysis, with Special Reference to Education, University of Chicago Press.

3. Bowles S. and Gintis, H., 1975. The problem with human capital theory: a Marxian Critique, American Economic Review, Vol. 165 No. 2, pp. 74-82

4. Bradley S., 1995. The Youth Training Scheme: a critical review of the evaluation literature, International Journal of Manpower, Vol. 16 No. 4, pp. 30-56.

5. Chapman P.G., 1993. The Economics of Training, Harvester, Manchester, Lisbon.

6. Middleton J., Ziderman A., Adams A., 1991, Vocational and Technical Education and Training, The World Bank. New York. 
7. Reynolds L., Masters S. and Moser C., 1986. Labor Economics and Labor Relations, Prentice Hall, Englewood Cliffs, NJ, pp. 165-6.

8. Schultz T. W., 1961. Investment in Human Capital, The American Economic Review 1(2), $1-17$.

9. Spence M. 1975. Job market signaling, Quarterly Journal of Economics, Vol. 87, pp. 355.

10. Tomé E., 2001, The evaluation of vocational training: a comparative analysis, Journal of European and Industrial Training, volume 25, number 7, pgs 380-8.

11. Tomé E., 2009. The evaluation of HRD: a critical study with application, Journal of European Industrial Training Volume 33, Issue 6, pp 513-538.

12. Tomé E., 2013. The European Social Fund: A Very Specific Case Instrument of HRD Policy, European Journal of Training and Development, Volume 37, Issue 4, pp.336 - 356.

13. Council Regulation (EC) No 1083/2006 of 11 July 2006 laying down general provisions on the European Regional Development Fund, the European Social Fund and the Cohesion Fund and repealing Regulation (EC) No 1260/1999, Oficial Journal of the European Union, 2006, L 210/25.

14. Council Regulation (EC) No 1260/1999 of 21 June 1999 laying down general provisions on the Structural Funds, Oficial Journal of the European Union, 1999, L 161/1.

15. Council Regulation (EC, Euratom) No 2988/95 of 18 December 1995 on the protection of the European Communities financial interests, Official Journal of the European Union, L 312, 23/12/1995.

16. Explanatory Report on the Second Protocol to the Convention on the protection of the European Communities' financial interests (Text approved by the Council on 12 March 1999) Official Journal of the European Union, C091, 31/03/1999.

17. Consolidated Version of the Treaty on European Union, Official Journal of the European Union, 2010, C 83/13.

18. Treaty of Amsterdam amending the Treaty on European Union, the Treaties establishing the European Communities and other related acts, 97/C340/01.

19. European Commission proposal for multiannual financial framework 2014 - 2020, Office for Official Publications of the European Union, 2011 ISBN 978-92-79-21299-4, OI: 10.2761/80451, European Union, 2011.

20. National Reform Program 2011 - 2013, the Government of Romania, Bucharest, 2011. 